\title{
Genetic Diversity and Drug Resistance Mutations in HIV-1 from Untreated Patients in Niamey, Niger
}

\author{
Saïdou Mamadou, ${ }^{1,2}$ Yahayé Hanki, ${ }^{3}$ Amadou Roufaï Ali Maazou, ${ }^{2}$ \\ Balki Aoula, ${ }^{2}$ and Sanata Diallo ${ }^{4}$ \\ ${ }^{1}$ Laboratory of Bacteriology-Virology, Faculty of Health Sciences, Abdou Moumouni University, P.O. Box 237, Niamey, Niger \\ ${ }^{2}$ National Reference Laboratory for STI/HIV/TB, P.O. Box 10 146, Niamey, Niger \\ ${ }^{3}$ Centre de Traitement Ambulatoire (CTA) of Niamey, P.O. Box 11 236, Niamey, Niger \\ ${ }^{4}$ Solidarité Thérapeutique et Initiative Contre le Sida (SOLTHIS), P.O. Box 10 393, Niamey, Niger
}

Correspondence should be addressed to Saïdou Mamadou, saidou_mamadou@yahoo.fr

Received 10 August 2011; Accepted 17 September 2011

Academic Editors: A. L. Chenine and M. Shehu-Xhilaga

Copyright ( $) 2011$ Saïdou Mamadou et al. This is an open access article distributed under the Creative Commons Attribution License, which permits unrestricted use, distribution, and reproduction in any medium, provided the original work is properly cited.

The objective of the study was to estimate the prevalence of transmitted resistance to antiretroviral of HIV-1 circulating in Niger. We collected plasmas from 96 drug-naive patients followed up in the main HIV/AIDS Care Center of Niamey, the capital city of Niger. After RNA extraction and retrotranscription to proviral DNA, nested PCR was performed to amplify PR (codons 199) and RT (codons 1-240) fragments for sequencing. Sequences were analysed for phylogeny, then for resistance-associated mutations according to IAS-USA and Stanford's lists of mutations. We characterized six HIV-1 genetic variants: CRF02-AG (56.3\%), CRF30_0206 (15.6\%), subtype G (15.6\%), CRF06_cpx (9.4\%), CRF11_cpx (2.1\%), and CRF01_AE (1\%). About 8.3\% of HIV strains had at least 1 resistance mutation: 4 strains with at least 1 mutation to NRTI, 5 for NNRTI, and 1 for PI, respectiveley $4.2 \%, 5.2 \%$, and $1.0 \%$. These preliminary results gave enough information for the need of instauring HIV drug resistance national surveillance.

\section{Introduction}

HIV-1 strains belong to four groups of genetic variants $(\mathrm{M}, \mathrm{N}, \mathrm{O}, \mathrm{P})$, which may represent four separate introductions of simian immunodeficiency viruses to humans. Into group $\mathrm{M}$, mutations caused by retrotranscription errors generated nine subtypes $(\mathrm{A}, \mathrm{B}, \mathrm{C}, \mathrm{D}, \mathrm{F}, \mathrm{G}, \mathrm{H}$, J, and $\mathrm{K}$ ) of HIV-1 [1]. Genetic recombination events during multiple infections provided various mosaic viruses: 49 circulating recombinant forms (CRFs) to date (http://www.hiv.lanl.gov/ content/sequence/HIV/CRFs/CRFs.html) and many unique recombinants. Almost all these HIV-1 genetic variants cocirculate in Africa. In Niger, a sub-Saharan country with HIV prevalence under $1 \%$ in general population, none-B subtypes, and CRFs cocirculate, with large predominance of CRF02_AG and CRF06_cpx [2,3].
The National Programme for Antiretroviral (ARV) Therapy Access started in this country in November 2004 more than six thousand people were treated, at the end of 2010. First-line association was stavudine/lamivudine/nevirapine, then zidovudine/lamivudine/nevirapine since 2004; Tenofovir and efavirenz were used instead of stavudine (or zidovudine) and nevirapine for patients coinfected with hepatitis $B$ virus.

World Health Organization (WHO) recommends to countries two stringent methods for HIV drug resistance (HIVDR) surveillance: the HIVDR-Threshold survey to assess transmitted resistance prevalence among untreated patients and the HIVDR monitoring for patients treated during 12 months. Before constitution of an operational HIVDR task force in Niger, we conducted the present study which aimed to estimate the genetic diversity and the transmission 
rate of HIV-1 drug resistance in untreated patients in 2009 in Niamey, by using an alternative sampling strategy.

\section{Materials and Methods}

This prospective and analytic survey was conducted during 3 months, from October to December 2009, for plasma collection. We got samples from 96 consecutive ARV drug-naive HIV-1-infected patients, under periodic medical followup at "Centre de Traitement Ambulatoire" of Niamey, the national HIV/AIDS-Specific Care Center of Niger.

HIV-1 RNA was extracted from plasma with the COBAS AmpliPrep Total Nucleic Acid Isolation kit (Roche), and amplified by a one-step reverse transcription-PCR using the TITAN One Tube Reverse Transcription PCR kit (Roche), with outer primers $5^{\prime} \mathrm{P} 1$ and $3^{\prime} \mathrm{P} 1$ for PR and RTAG1 and RTAG2 for RT. Nested PCR was then performed using AmpliTaq Polymerase (Applied Biosystems), with inner primers 5'P2 and 3'P2 for PR and RTAG3 and RTAG4 for RT.

Amplified fragments, PR (codons 1-99) and RT (codons 1-240), were sequenced using the BigDye Terminator Cycle Sequencing Ready Reaction kit (Applied Biosystems), with ABI 3100 Genetic Analyzer (PE Applied Biosystems). Sequences were analysed using the Sequence Navigator software (PE Applied Biosystems), comparing the sense and antisense strands of each fragment with the prototype virus HXB2 sequence.

For genetic subtype determination, new PR and RT sequences were aligned with sequences from reference strains of all subtypes and CRFs, using the CLUSTAL W program [4]. Phylogenetic trees were constructed using the neighbour-joining method and the Kimura two-parameter model. One hundred replicates were evaluated by phylogenetic analysis. With the bootscanning method of SimPlot software, possible recombination breakpoints and subtypes involved were determinate.

For resistance mutation detection, amino acid sequences were compared with HXB2 consensus reference and analysed according to the 2007 International AIDS Society-United States of America (IAS-USA) and the Stanford lists of mutations $[5,6]$.

For the calculation of $95 \%$ confidence intervals (Fleiss quadratic method) and the percentages comparison, we used Epi Info 6 Software.

This study was approved by the Ministry of Health, as a regular activity of the National Initiative for ARV Access in Niger.

\section{Results}

Out of the 96 patients, 32 were men (33\%) and 64 were women (67\%). The median age was 36 years (range: $23-88$ ). All the patients have said to be heterosexual. The median of CD4 cell count was 291 cells $/ \mathrm{mm}^{3}$ (range: $1-1145$ ): $36.5 \%$ had more than 350 cells $/ \mathrm{mm}^{3}$ (group 1), 34.4\% had 200 to 350 cells $/ \mathrm{mm}^{3}$ (group 2), and $29.2 \%$ had lower than 200 cells $/ \mathrm{mm}^{3}$ (group 3).

Phylogenetic analysis showed the presence of subtype $\mathrm{G}$ and five different HIV-1 Circulating Recombinant Forms
(CRFs): CRF01_AE, CRF02-AG, CRF06_cpx, CRF11_cpx, and CRF30_0206. The distribution of the different genetic variant is showed in Table 1.

After analysis of PR and RT sequences according to the 2007 IAS-USA list of mutations, 8 patients had a strain with at least one resistance mutation, so $8.3 \%$ (95\% CI: $3.9-$ $16.2 \%)$. The frequency of these strains was $8.57 \%(3 / 35)$, $9.09 \%(3 / 33)$, and $7.17 \%(2 / 28)$ among group 1, group 2, and group 3 patients, respectively, $(P=0.9611)$.

The different profiles are showed in Table 2. We found 4 strains with at least 1 mutation to NRTI, 5 for NNRTI and 1 for PI, so, respectively, 4.2\% (CI 95\%: 1.3-10.9\%), 5.2\% (CI 95\%: $1.9-12.3 \%$ ) and, $1.0 \%$ (CI 95\%: 0.0-6.5\%).

\section{Discussion}

For the study of HIV-transmitted (or primary) drug resistance, it is better to target recent infections (less than 6 months). It can be identified by using an indirect ELISA which quantify antibodies specific for consensus V3 peptides and consensus peptides of the immunodominant epitope gp41 [7]. This test was not done in this study, but CD4 count indicated that $63.5 \%$ of our patients had less than 350 cells $/ \mathrm{mm}^{3}$, so already eligible for starting antiretroviral treatment, according to the recent WHO recommendations.

The results of phylogenetic analysis confirmed the predominance of CRF02_AG in Niger, previously reported in a genetic diversity study in env and gag genes [2]. The variation of rate for this CRF, from $50 \%$ in 2000 to $56.3 \%$ in 2009 , was not significant $(P=0.4331)$. CRF06_cpx decreased from $18.1 \%$ to $9.4 \%$, but not significantly $(P=0.1011)$. The rate of CRF30_020, described for the first time in Niger, varied from $9.1 \%$ in 2000 to $15.6 \%$ in $2009(P=0.2238)$ [8]. Only the variation for subtype G, from $3.1 \%$ to $15.6 \%$, was significant $(P=0.0031)$. CRF01_AE and CRF11_cpx were newly reported in the country.

About HIVDR, these results showed that, despite the relatively recent ARV introduction in the Niger, more than $8 \%$ of untreated patients were infected by an HIV strain with at least one resistance mutation, mainly to NTRI and NNRTI. Such patients, when beginning ARV treatment, have a higher risk of virologic failure, despite the regimen originally being fully active $[9,10]$. The overall prevalence of transmitted resistance was $11.5 \%$ in 2006 in Mali, a neighbouring country, using the same alternative method [11]; but studies from some others Sub-Saharan countries have reported rates lower than $5 \%$, by using the WHO standard protocol and the WHO list of resistance mutations for epidemiological surveys [12-17].

According to the immunological status (CD4 number), we have not found significant difference of mutant strains rate $(P=0.9611)$.

Two CRF02_AG carried resistance mutations for two ARV classes. One strain carried Y181C and M46L. Y181CIV, as K103NS, is associated with higher levels of phenotypic resistance or clinical evidence for reduced virological response. M46L is known to be associated with tipranavir, lopinavir, and indinavir resistance. The second strain had seven mutations: M184V, L74V, M41L, L210W, T215Y, Ins69, 
TABle 1: Distribution of HIV-1 genetic variants among untreated patients.

\begin{tabular}{lcc}
\hline Genetic variant & Number & $\%$ \\
\hline Subtype G & 15 & 15.6 \\
CRF01_AE & 1 & 1.0 \\
CRF02_AG & 54 & 56.3 \\
CRF06_cpx & 9 & 9.4 \\
CRF11_cpx & 2 & 2.1 \\
CRF30_0206 & 15 & 15.6 \\
\hline Total & 96 & 100 \\
\hline
\end{tabular}

TABLE 2: Resistance mutations described for the 8 strains.

\begin{tabular}{lcccc}
\hline Patient code & Subtype & NRTI & NNRTI & PI \\
\hline 1799CTA09 & G & & K103N & \\
1814CTA09 & G & Y115F & & \\
1847CTA09 & CRF02_AG & & Y181C & M46L \\
1867CTA09 & CRF06_cpx & T69S & & \\
1863CTA09 & CRF02_AG & T69N & & \\
& & M41L, Ins69, & & \\
1949MVS & CRF02_AG & L74V, M184V, & K103N & \\
& & L210W, T215Y & & \\
1908CTA09 & CRF02_AG & & K103N & \\
815CTA07 & CRF02_AG & & K103N & \\
\hline
\end{tabular}

and $\mathrm{K} 103 \mathrm{~N}$. Two of them are not associated with resistance, but rather increase drug susceptibility: M184VI for ZDV, TDF and d4T $[18,19]$, and L74V for ZDV, and TDF [20, 21]. M41L, L210W and T215Y are three thymidine analog mutations (TAMs), associated with phenotypic resistance or clinical evidence for reduced virological response, mainly to stavudine and zidovudine, but also resistance to abacavir, didanosine, and tenofovir.

In conclusion, these preliminary data confirmed the need to assure HIVDR surveillance in Niger, in order to complete the global medical monitoring of HIV patients. We plan to start in August 2011 our adapted WHO's standard protocol, including monitoring of resistance mutations for treated patients and the transmitted resistance threshold survey. These stringent conditions may offer data more comparable with those from other African countries.

\section{Acknowledgments}

This work was funded in part by a special convention between the Ministry of Health of Niger (represented by the HIV/AIDS Programme) and the "Solidarité Thérapeutique et Initiative contre le Sida (SOLTHIS, France). The authors acknowledge the staff of SOLTHIS, mainly Professor Christine Katlama, Dr. Louis Pizzaro, Dr. Florence Huber from the Head Office in Paris (France), and Mrs. Stéphanie Tchiombiano, Mr. Pierre Teissere from Local Office in Niamey (Niger). They acknowledge also Professor Vincent Calvez and Dr. Anne-Geneviève Marcelin, from the Department of Virology, Pitié-Salpêtrière Hospital of Paris (France), for their technical support. Yahayé Hanki is the director of Centre de Traitement Ambulatoire (CTA) of Niamey, Niger. Sanata Diallo is the medical director of Niger mission of Solidarité Thérapeutique et Initiative contre le Sida (SOLTHIS), Niger.

\section{References}

[1] D. L. Robertson, J. P. Anderson, J. A. Bradac et al., "HIV-1 nomenclature proposal," Science, vol. 288, no. 5463, pp. 55$57,2000$.

[2] S. Mamadou, R. M. Cissé, A. R. Ali Maazou et al., "Séroprévalence de l'infection à VIH en population générale au Niger en 2006," Annales de l'Université Abdou Moumouni de Niamey, vol. XI-A, pp. 20-23, 2010.

[3] S. Mamadou, C. Montavon, A. Ben et al., "Predominance of CRF02-AG and CRF06-cpx in Niger, West Africa," AIDS Research and Human Retroviruses, vol. 18, no. 10, pp. 723-726, 2002.

[4] J. D. Thompson, D. G. Higgins, and T. J. Gibson, "CLUSTAL $\mathrm{W}$ : improving the sensitivity of progressive multiple sequence alignment through sequence weighting, position-specific gap penalties and weight matrix choice," Nucleic Acids Research, vol. 22, no. 22, pp. 4673-4680, 1994.

[5] V. A. Johnson, F. Brun-Vézinet, B. Clotet et al., "Update of the drug resistance mutations in HIV-1: December 2010," Topics in HIV Medicine, vol. 18, no. 5, pp. 156-163, 2010.

[6] R. W. Shafer, S. Y. Rhee, D. Pillay et al., "HIV-1 protease and reverse transcriptase mutations for drug resistance surveillance," AIDS, vol. 21, no. 2, pp. 215-223, 2007.

[7] F. Barin, L. Meyer, R. Lancar et al., "Development and validation of an immunoassay for identification of recent human immunodeficiency virus type 1 infections and its use on dried serum spots," Journal of Clinical Microbiology, vol. 43, no. 9, pp. 4441-4447, 2005.

[8] S. Mamadou, N. Vidal, C. Montavon et al., "Emergence of complex and diverse CRF02-AG/CRF06-cpx recombinant HIV type 1 strains in Niger, West Africa," AIDS Research and Human Retroviruses, vol. 19, no. 1, pp. 77-82, 2003.

[9] S. J. Little, S. Holte, J. P. Routy et al., "Antiretroviral-drug resistance among patients recently infected with HIV," The New England Journal of Medicine, vol. 347, no. 6, pp. 385-394, 2002.

[10] E. S. Daar and D. D. Richman, "Confronting the emergence of drug-resistant HIV type 1: impact of antiretroviral therapy on individual and population resistance," AIDS Research and Human Retroviruses, vol. 21, no. 5, pp. 343-357, 2005.

[11] A. Derache, A. I. Maiga, O. Traore et al., "Evolution of genetic diversity and drug resistance mutations in HIV-1 among untreated patients from Mali between 2005 and 2006," Journal of Antimicrobial Chemotherapy, vol. 62, no. 3, pp. 456-463, 2008.

[12] A. Ayouba, T. T. X. Lien, J. Nouhin et al., "Low prevalence of HIV type 1 drug resistance mutations in untreated, recently infected patients from burkina Faso, Côte d'Ivoire, senegal, Thailand, and Vietnam: the ANRS 12134 study," AIDS Research and Human Retroviruses, vol. 25, no. 11, pp. 11931196, 2009.

[13] A. F. Aghokeng, L. Vergne, E. Mpoudi-Ngole et al., "Evaluation of transmitted HIV drug resistance among recently-infected antenatal clinic attendees in four Central African countries," Antiviral Therapy, vol. 14, no. 3, pp. 401-411, 2009.

[14] N. Ndembi, F. Lyagoba, B. Nanteza et al., "Transmitted antiretroviral drug resistance surveillance among newly HIV 
type 1-diagnosed women attending an antenatal clinic in Entebbe, Uganda," AIDS Research and Human Retroviruses, vol. 24 , no. 6, pp. 889-895, 2008.

[15] H. Bussmann, F. de la Hoz Gomez, T. H. Roels et al., "Prevalence of transmitted HIV drug resistance in Botswana: lessons learned from the HIVDR-threshold survey conducted among women presenting for routine antenatal care as part of the 2007 national sentinel survey," AIDS Research and Human Retroviruses, vol. 27, no. 4, pp. 365-372, 2011.

[16] K. Kamoto and J. Aberle-Grasse, "Surveillance of transmitted HIV drug resistance with the World Health Organization threshold survey method in Lilongwe, Malawi," Antiviral Therapy, vol. 13, supplement 2, pp. 83-87, 2008.

[17] G. Maphalala, V. Okello, S. Mndzebele et al., "Surveillance of transmitted HIV drug resistance in the Manzini-Mbabane corridor, Swaziland, in 2006," Antiviral Therapy, vol. 13, no. 2, pp. 95-100, 2008.

[18] J. M. Whitcomb, N. T. Parkin, C. Chappey, N. S. Hellmann, and C. J. Petropoulos, "Broad nucleoside reverse-transcriptase inhibitor cross-resistance in human immunodeficiency virus type 1 clinical isolates," Journal of Infectious Diseases, vol. 188, no. 7, pp. 992-1000, 2003.

[19] K. Diallo, M. Götte, and M. A. Wainberg, "Molecular impact of the M184V mutation in human immunodeficiency virus type 1 reverse transcriptase," Antimicrobial Agents and Chemotherapy, vol. 47, no. 11, pp. 3377-3383, 2003.

[20] E. R. Lanier, N. Givens, C. Stone et al., "Effect of concurrent zidovudine use on the resistance pathway selected by abacavircontaining regimens," HIV Medicine, vol. 5, no. 6, pp. 394399, 2004.

[21] S. Y. Rhee, J. Taylor, G. Wadhera, A. Ben-Hur, D. L. Brutlag, and R. W. Shafer, "Genotypic predictors of human immunodeficiency virus type 1 drug resistance," Proceedings of the National Academy of Sciences of the United States of America, vol. 103, no. 46, pp. 17355-17360, 2006. 

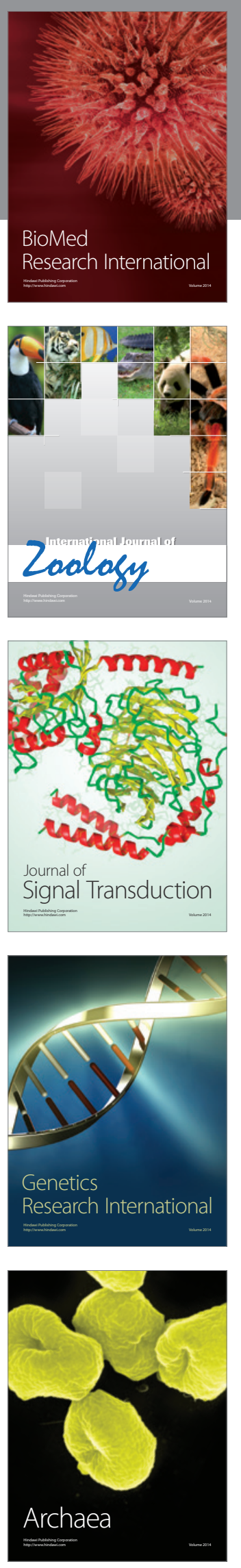
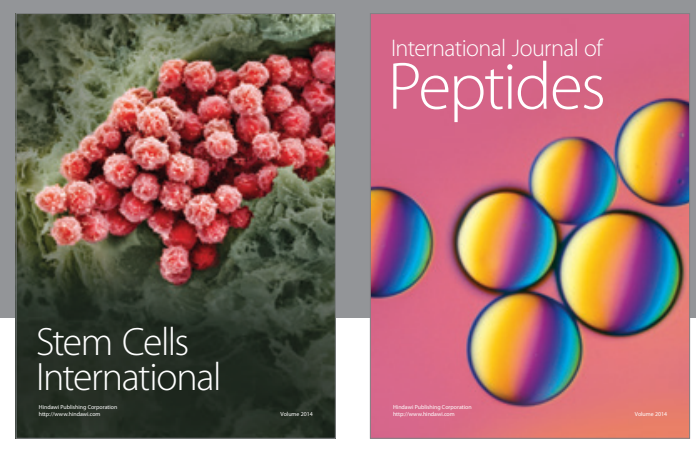

Submit your manuscripts at

http://www.hindawi.com
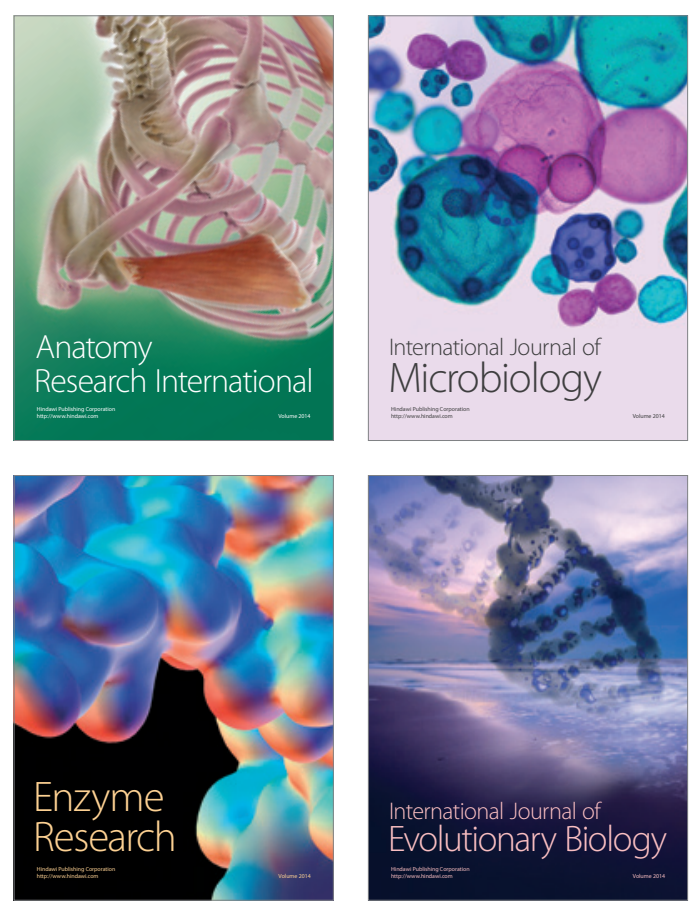
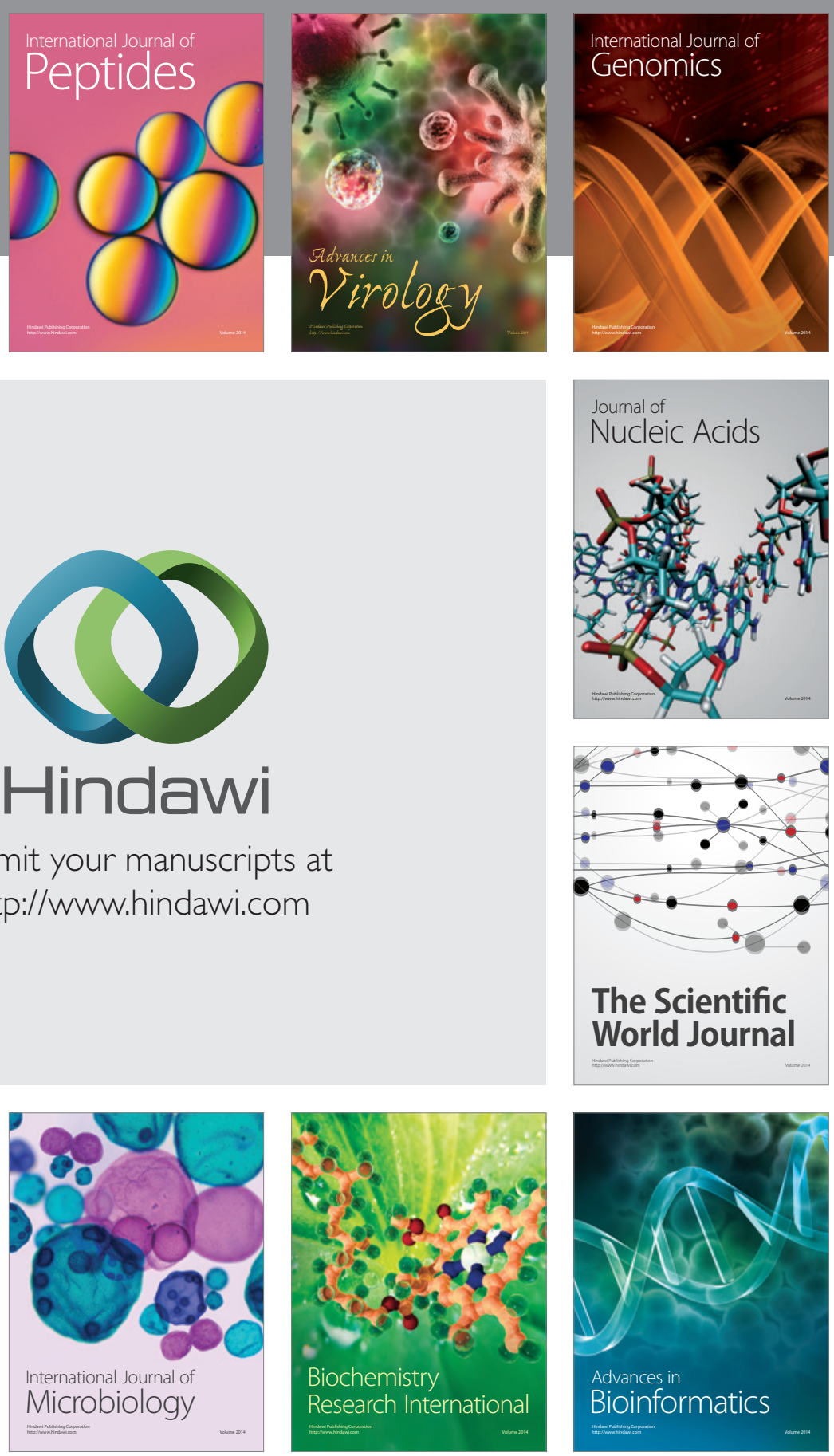

The Scientific World Journal
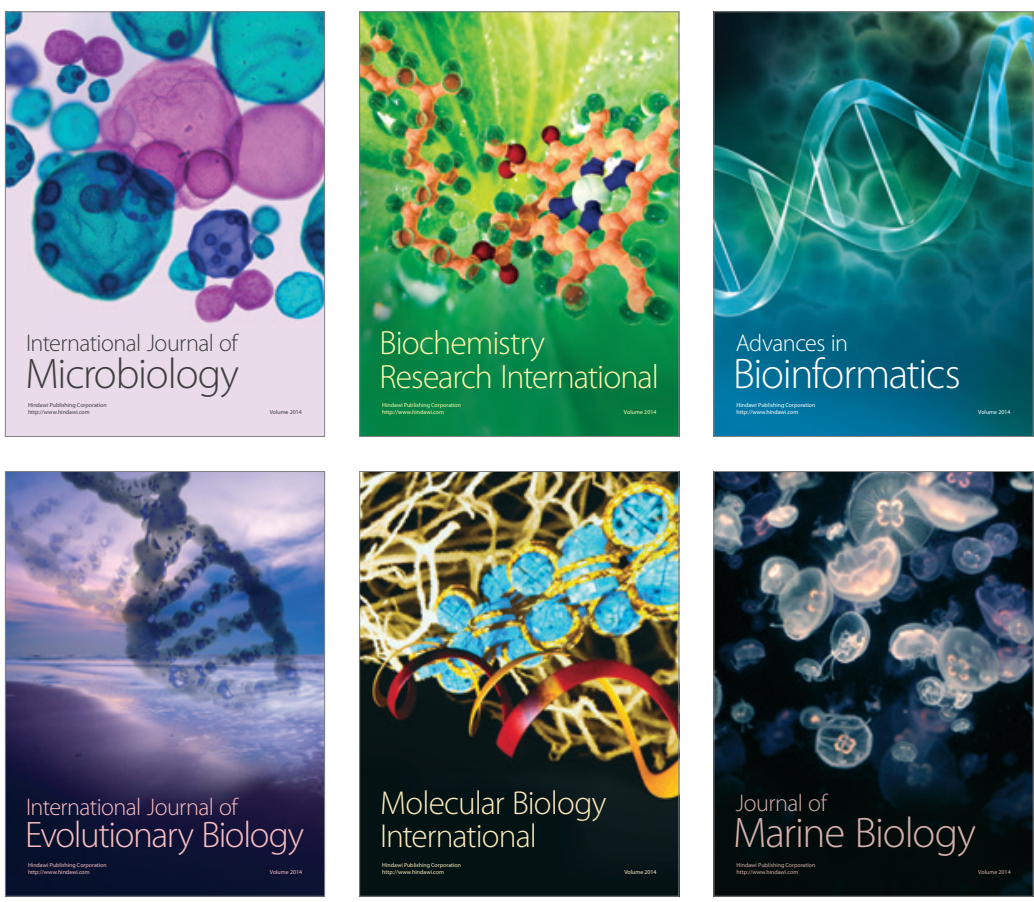